\title{
Case Report : Multiple Stress Fractures (hamate, triquetrum, 2nd, 3rd, and 4th Metacarpal bones) in an Amateur Tennis Player
}

\author{
Hatim Mohammed A. Alshareef, Alhusain Mohammad Alshareef, and Mohammed Hussein AlKaff
}

\begin{abstract}
Background: upper extremity stress fractures are infrequent events in tennis sport. According to our literature, we have only identified 6 case reports of upper limb stress fractures among amateur or professional tennis players. To the best of our knowledge, this is the only case report where stress fractures occur in: hamate, triquetrum, 2nd, 4th, and 5th metacarpal bones simultaneously.

Case presentation: 27 years old lady, presented with acute burning pain at the base of her right thumb. There was not a history of direct trauma. Her symptoms start to appear after 3 days of playing tennis. Physical examination was negative for tenderness, swelling and erythema. The rheumatoid factor was elevated $(20.3 \mathrm{iu} / \mathrm{ml})$. the diagnosis of multiple stress fractures was made by the suggestive MRI findings.

Conclusion: Although stress fractures of the upper limbs are not common, it is of a great value to keep the clinical suspicion high towards it. Especially in amateur or professional athletes with persistent or worsening symptoms. The best modality to confirm such fractures is MRI.
\end{abstract}

Index Terms - Stress fractures, upper limb, upper extremity, tennis.

\section{INTRODUCTION}

Upper extremities stress fractures are considered rare incidences in the field of sports medicine [1-5]. Moreover, tennis is not believed to be a predisposing sport for such an injury in comparison to other sports $[6,7]$. According to literature, there are six case reports of stress fractures in tennis players: three in metacarpal bone (MCB), two in hamate, and one in scaphoid [8-13]. To the best of our knowledge, the case we are reporting is the only case in which the patient is presented with stress fractures in hamate, triquetrum, 2nd, 4th, and 5th MCB's simultaneously during playing tennis.

\section{CASE REPORT:}

A 27 years old lady presented to the emergency department with acute onset of pain in the base of her right thumb. The pain was burning in nature and was not aggravated by movement. She reported that she was engaged in tennis playing for 3 days before her symptoms appeared. She was trained for one hour per day and couched to handle the racquets by the Western grip. No direct trauma to her hand was reported during her training or after.

Published on May 22, 2020.

Hatim Mohammed A. Alshareef, King Fahd Armed Forces Hospital, Saudi Arabia. (corresponding e-mail: dr.hatim.alshareef@gmail.com)

Alhusain Mohammad Alshareef, King Saud bin Abdulaziz University for Health Sciences, Saudi Arabia.

Mohammed Hussein AlKaff, Samir Abbas Hospital, Saudi Arabia.
The physical examination was generally unremarkable since no swelling or erythema was detected. However, laboratory investigations revealed an elevated Rheumatoid factor $(20.3 \mathrm{iu} / \mathrm{ml})$. The diagnosis of multiple stress fractures was made upon MRI findings.

On radiological evaluation, $\mathrm{x}$-ray was unremarkable (Figure 1 and 2). Whereas, MRI showed multiple areas of bone marrow edema at the base of the 2nd, 4th, 5th metacarpal bones as well as hamate and triquetrum bones (Figure 3 and 4).

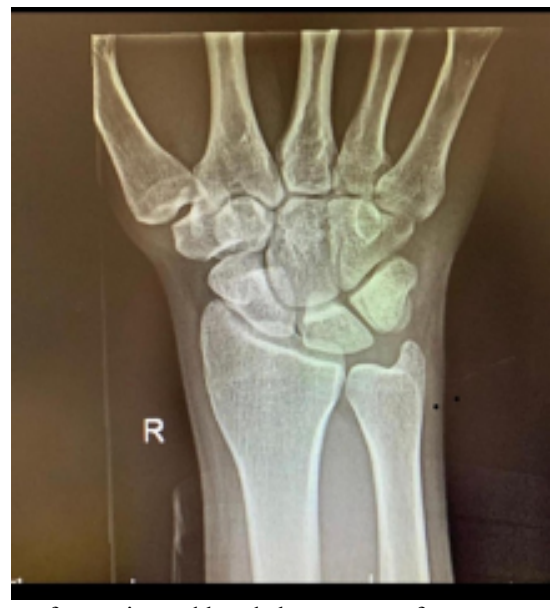

Fig. 1. x Ray of ap wrist and hand shows query fracture over MCB and Carpal bones.

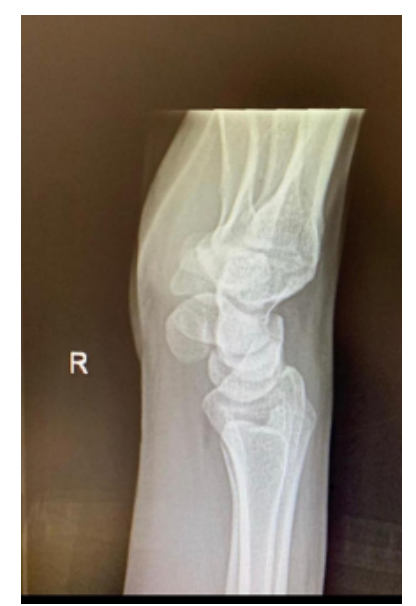

Fig. 2. Lateral view of wrist shows fracture over 3th 4th MCB. 


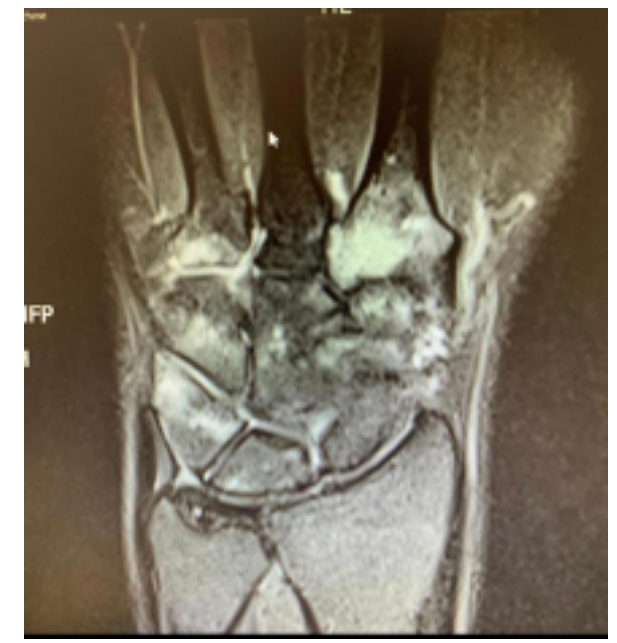

Fig. 3. MRI showed stress fracture over MCB and Carpal.

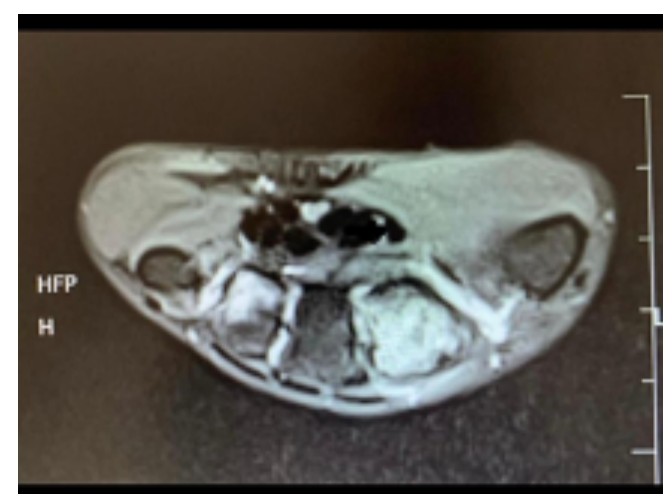

Fig. 4. MRI shows stress fracture over MCB with edema.

\section{DiscuSSION}

It is a fact that stress fractures primarily occur in the lower limbs. However, according to Balius R et al. the upper limbs stress fractures including humerus, ulna, scaphoid, metacarpals and phalanges are becoming more frequent [6].

The increase in training intensity and thus the repeated movement against the palm by the racquet can explain the mechanism of stress injuries to carpal bones in tennis players $[6,8,9]$. Nonetheless, the patient in our case report had a limited engagement ( 3 days only) in the sport before the injury developed.

In a more detailed manner, according to Balius $\mathrm{R}$ et al. case series, 2nd metacarpal bone was the most common site of stress fracture among all other metacarpals [6]. It was proposed that since the 2nd metacarpal bone is the longest of all metacarpals and its linkage to the 1st, 3rd metacarpals, trapezoid, trapezium and capitate by multiple strong ligaments, grasping a racquet or any other tool makes maximum tension at the base of 2 nd metacarpal bone amplified [6].

The poor stroke technique and the type of grip could also be considered as predisposing factors to stress fractures $[6,8,9]$. In fact, it was first noticed by Lombardo that the Western grip might have a significant effect on the production of such injuries, and this was furtherly supported by Kuriyama and Bespalchuk et al. [10,14,15]. This, in part, can explain the susceptibility in our patient for her fractures.

The only laboratory abnormality we detected in our case was the elevated rheumatoid factor $(20.3 \mathrm{iu} / \mathrm{ml})$. we did not find in our literature any study that could describe the association between elevated rheumatoid factor and the incidence of stress fractures. However, Nampei A el al. showed in his study that rheumatic arthritis (RA) patients are at a significant increased risk for stress fractures [16]. In despite of this fact, our patient is not confirmed to have RA, since the rheumatoid factor is not of a high specific value, and thus further investigations are needed [17].

\section{CONCLUSION}

We have presented a case report of a young lady with multiple stress fractures in: hamate, triquetrum, $2 \mathrm{nd}, 3 \mathrm{rd}$, and 4th Metacarpal bones. The modality on which our diagnosis relied upon was the MRI evaluation. The clinical suspicion of stress fractures should always be maintained in amateur and professional athletes, regardless of their initial x-rays. Especially, if their symptoms get progressively worse. Therefore, we recommend that the most effective investigation to confirm stress fracture is MRI.

\section{REFERENCES}

[1] Arendt E, Agel J, Heikes C, Griffiths H. Stress injuries to bone in college athletes: a retrospective review of experience at a single institution. The American journal of sports medicine. 2003 Jun;31(6):959-68.

[2] Jones GL. Upper extremity stress fractures. Clinics in sports medicine. 2006 Jan 1;25(1):159-74.

[3] Matheson GO, Clement DB, McKenzie DC, Taunton JE, Lloyd-Smith DR, MacIntyre JG. Scintigraphic uptake of $99 \mathrm{~m}$ Tc at non-painful sites in atheles with stress fractures: the concept of bone strain. Sports Med. 1987;4:65-75.

[4] Matheson GO, Clement DB, McKenzie DC, Taunton JE, Lloyd-Smith DR, Macintyre JC. Stress fractures in athletes: a study of 320 cases. Am J Sports Med. 1987; 15:46-58.

[5] Roca J, Cabot J. Fracturas por sobrecarga en el deportista: apunts. Medicina de l'esport. 1985;22:17-28.

[6] Balius R, Pedret C, Estruch A, Hernández G, Ruiz-Cotorro Á, Mota J. Stress fractures of the metacarpal bones in adolescent tennis players: a case series. The American journal of sports medicine. 2010 Jun;38(6):1215-20.

[7] Maquirriain J, Ghisi JP. The incidence and distribution of stress fractures in elite tennis players. British journal of sports medicine. 2006 May 1;40(5):454-9.

[8] Duarte ML, da Nóbrega RR, de Almeida Prado JL, Scoppetta LC. Metacarpal stress fracture in amateur tennis player-an uncommon fracture. Revista Brasileira de Ortopedia (English Edition). 2017 Sep 1;52(5):608-11.

[9] Muramatsu K, Kuriyama R. Stress fracture at the base of second metacarpal in a soft tennis player. Clinical Journal of Sport Medicine. 2005 Jul 1;15(4):279-80.

[10] Bespalchuk A, Okada K, Nishida J, Takahashi S, Shimada Y, Itoi E. Stress fracture of the second metacarpal bone. Skeletal radiology. 2004 Sep 1;33(9):537-40.

[11] Kohyama S, Kanamori A, Tanaka T, Hara Y, Yamazaki M. Stress fracture of the scaphoid in an elite junior tennis player: a case report and review of the literature. Journal of medical case reports. 2016 Dec; $10(1): 8$

[12] Josipovic M, Bozic D, Bohacek I, Smoljanovic T, Bojanic I. Hamate hook nonunion initially mistaken for ulnar nerve compression: a case report with review of literature. Wiener klinische Wochenschrift. 2017 Feb 1;129(3-4):136-40.

[13] Guha AR, Marynissen H. Stress fracture of the hook of the hamate. British journal of sports medicine. 2002 Jun 1;36(3):224-5.

[14] Waninger KN, Lombardo JA. Stress fracture of index metacarpal in an adolescent tennis player. Clinical journal of sport medicine: official journal of the Canadian Academy of Sport Medicine. 1995;5(1):63-6.

[15] Muramatsu K, Kuriyama R. Stress fracture at the base of second metacarpal in a soft tennis player. Clinical Journal of Sport Medicine. 2005 Jul 1;15(4):279-80. 
[16] Nampei A, Hashimoto J, Koyanagi J, Ono T, Hashimoto H, Tsumaki N, Tomita T, Sugamoto K, Nishimoto N, Ochi T, Yoshikawa H. Characteristics of fracture and related factors in patients with rheumatoid arthritis. Modern rheumatology. 2008 Apr 1;18(2):170-6.

[17] Shmerling RH, Delbanco TL. The rheumatoid factor: an analysis of clinical utility. The American journal of medicine. 1991 Nov 1;91(5):528-34. 